\title{
European Federation of Societies for Ultrasound in Medicine and Biology (EFSUMB): An Update on the Pediatric CEUS Registry on Behalf of the "EFSUMB Pediatric CEUS Registry Working Group" Register der Europäischen Ultraschallgesellschaft (EFSUMB): Update „Anwendung des kontrastverstärkten Ultraschalls bei Kindern“
}

Authors

Christoph F. Dietrich ${ }^{1,2,3}$, Rasa Augustiniene ${ }^{4}$, Tomasz Batko ${ }^{5}$, Vito Cantisani ${ }^{6}$, Andrius Cekuolis ${ }^{4}$, Annamaria Deganello7, Yi Dong ${ }^{8}$, Doris Franke ${ }^{9}$, Zoltan Harkanyi ${ }^{10}$, Paul D. Humphries ${ }^{11}$, Maciej Jędrzejczyk ${ }^{12}$, Jörg Jüngert ${ }^{13}$, Horst Kinkel ${ }^{14}$, Orsolya Koller ${ }^{10}$, Wojciech Kosiak ${ }^{15}$, Christian Kunze ${ }^{16}$, Anoushka Ljutikov ${ }^{17}$, Jaroslaw Madzik ${ }^{18}$, Hans-Joachim Mentzel ${ }^{19}$, Maciej Piskunowicz ${ }^{20}$, Vasileios Rafailidis ${ }^{7}$,

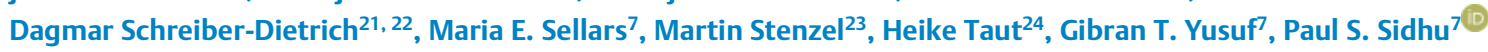

\section{Affiliations}

1 Department Allgemeine Innere Medizin (DAIM), Kliniken Hirslanden Beau Site, Salem und Permanence, Bern, Switzerland

2 Department of Internal Medicine 2, Caritas-Krankenhaus Bad Mergentheim, Germany

3 Johann Wolfgang Goethe University Hospital, Frankfurt/ Main, Germany

4 Department of Radiology, Children's Hospital, Affiliate of Vilnius University Hospital Santaros Klinikos, Lithuania

5 Department of Pediatric, Haematology and Oncology, Medical University of Gdansk, Poland

6 Radiological, Oncological and Anatomy-Pathological Sciences University Sapienza of Rome, Italy

7 Department of Radiology, King's College London, King's College Hospital, United Kingdom of Great Britain and Northern Ireland

8 Department of Ultrasound, Zhongshan Hospital, Fudan University, Shanghai, China

9 Department of Pediatric Kidney, Liver and Metabolic Diseases, Hannover Medical School, Hannover, Germany

10 Department of Radiology, Heim Pal National Pediatric Institute, Budapest, Hungary

11 Great Ormond Street Hospital for Children and University College London NHS Foundation Trusts

12 Ultrasound Diagnostic Department, Faculty of Medical Sciences, Medical University of Warsaw, Poland

13 Department of Pediatrics and Adolescent Medicine, University Hospital Erlangen, Friedrich-AlexanderUniversität Erlangen-Nürnberg, Erlangen, Germany

14 Krankenhaus Düren, Klinik für Gastroenterologie, Hepatologie, Diabetologie und Intensivmedizin, Düren, Germany

15 Ultrasound and Biopsy Diagnostics Lab at the Clinic of Pediatrics, Haematology and Oncology, Medical University of Gdansk, Poland
16 Clinic and Policlinic of Radiology, University Medical Center Halle (Saale), Germany

17 Department of Diagnostic Imaging, Barts Health NHS Trust, The Royal London Hospital, London, United Kingdom

18 Institute of Mother and Child, Department of Diagnostic Imaging, Warsaw, Poland

19 Section of Pediatric Radiology, Institute of Diagnostic and Interventional Radiology. University Hospital Jena, Germany

20 Department of Radiology, Medical University of Gdansk, Poland

21 Localinomed, Bern Switzerland

22 Department of Pediatric Medicine, Caritas-Krankenhaus Bad Mergentheim, Germany

23 Kliniken der Stadt Köln gGmbH, Kinderradiologie, Köln, Germany

24 Children's Hospital, Universitätsklinikum Dresden, Technische Universität Dresden, Dresden, Germany

Key words

guideline, SonoVue, safety, pediatrics

received 06.10.2020

accepted 24.12.2020

published online 09.03.2021

Bibliography

Ultraschall in Med 2021; 42: 270-277

DOI 10.1055/a-1345-3626

ISSN 0172-4614

(C) 2021. Thieme. All rights reserved.

Georg Thieme Verlag KG, Rüdigerstraße 14,

70469 Stuttgart, Germany 
Correspondence

Prof. Christoph F. Dietrich

Department Allgemeine Innere Medizin (DAIM), Kliniken

Hirslanden Beau Site, Salem und Permanence, Bern,

Switzerland, Schänzlihalde 11, 3013 Bern, Switzerland

Tel.: 0041313378870

ChristophFrank.Dietrich@hirslanden.ch,

http://orcid.org/0000-0001-6015-6347

Supplementary material is available under

https://doi.org/10.1055/a-1345-3626

\section{ABSTRACT}

The European Federation of Ultrasound in Medicine and Biology (EFSUMB) created the "EFSUMB Pediatric Registry" (EFSUMB EPR) with the purpose of collecting data regarding the intravenous application of pediatric contrast-enhanced ultrasound (CEUS). The primary aim was to document the current clinical practice and usefulness of the technique and secondarily to assess CEUS safety in children. We issue the preliminary results of this database and examine the overall practice of CEUS in children in Europe.

\section{ZUSAMMENFASSUNG}

Die Europäische Ultraschallgesellschaft (EFSUMB) initiierte eine Datensammlung zum pädiatrischen kontrastverstärkten Ultraschall. Die Ziele waren es, für die intravenöse Untersuchungstechnik Anwendungsmöglichkeiten und Technik zu dokumentieren sowie das Sicherheitsprofil bei Kindern zu reflektieren. Wir präsentieren hiermit die Ergebnisse für die Anwendung des kontrastverstärkten Ultraschalls in Europa.

\section{Introduction}

Ultrasound (US) is the first-line, optimal imaging technique in children, with advantages of high diagnostic yield, a wide range of applications, bedside investigation, real-time nature of imaging and direct interaction with the patient and parents. The use of magnetic resonance (MR) and computed tomography (CT) imaging in children has significantly increased, often entailing the use of general anesthesia or conscious sedation to achieve optimal imaging quality [1, 2]. Sedation or general anesthesia presents issues for parent and patient anxiety, as the imaging examination is more elaborate [3, 4]. An increased morbidity is evidenced by an incidence of hypoxemia at $2.9 \%$ and an examination failure rate of $7 \%$ in children who undergo sedation for MR and CT imaging procedures $[5,6]$. Conventional iodinated contrast agents in contrast-enhanced CT (CE-CT) and gadolinium agents in contrastenhanced MR (CE-MR) imaging are associated with a risk for anaphylactoid reactions [7-9], and there are possible long-term adverse effects with gadolinium retention in body tissue (skin, bone, brain, liver) following CE-MR imaging [9-11]. With CE-CT imaging, the radiation-associated cancer risk in children has been widely deliberated leading to the conclusion that there is a need to reduce radiation exposure in children [12-17].

Since 2002, intravenous contrast-enhanced ultrasound (CEUS) has been performed in children, with the potential to meet indications normally necessitating CE-CT and CE-MR examinations [18, 19]. Intravesical use of ultrasound contrast agents (UCA) for the evaluation of vesicoureteral reflux in children was first approved for Levovist (Schering AG, Berlin, Germany) and approved in 2016 by the European Medicines Agency (EMEA) for SonoVue (Bracco SpA, Milan) [20]. However, intravenous UCA application remains off label in children in European countries [21-23] and is approved for intravenous use in the United States of America only for the evaluation of focal liver lesions [24]. Off-label use (and reimbursement) of any drug remains a challenge in pediatric practice in Europe because many drugs are not subject to randomized trials in children and as a consequence are not specifically licensed for pediatric use [25-27]. The application of CEUS in children has been addressed by a European Federation of Ultrasound in Medicine and Biology (EFSUMB) position statement discussing the status of CEUS application in children [18].

There have been previous questionnaires and literature reviews with regard to the application of CEUS in children but no prospective recording of data related to intravenous CEUS application in children [19, 23, 28, 29]. The "EFSUMB Pediatric Registry (EFSUMB EPR)" was created with the purpose of collecting data related to pediatric CEUS. The primary aim is to document the technique's current range of deployment in European countries and potential value as an alternative to CE-CT and CE-MR imaging and secondly, to assesses and record the safety of CEUS in children. The potential for limiting exposure to radiation and nephrotoxic contrast agents was also ascertained, by recording the utility of the CEUS examination. The database was limited to the use of a single UCA, SonoVue as the sole agent licensed across European countries for adult indications, until the recent introduction of Sonazoid (GE Healthcare, Norway) in Norway for adult indications.

\section{Materials and Methods}

Ethics committee approval was requested and provided by the National Health Service (NHS, United Kingdom) Health Research Authority, via the South West Central Research Ethics Committee (European Pediatric Contrast-Enhanced Ultrasound Database 16/SW/0042 IRAS Project ID 164664). The study was approved as a database profile, with permission to upload anonymized data, with appropriate guardianship, and to allow access to bona fide research requests. Funding included EFSUMB support for the database and data analysis. The database was accessed via the EFSUMB website (http://www.efsumb-data.org/v1/login.asp). Following login and entering of credentials, anonymized cases studies could be uploaded. Two nominees of EFSUMB provided the guardianship (CFD, PSS) of the data collection. A sequential ID number was assigned to each patient during data entry. No identifiable data was collected on the website. The database was secured with access 
for uploading cases only. Access for research to the full database was possible with written requests to the guardians.

The database was advertised widely within the US imaging community of Europe via the EFSUMB website and at a number of US scientific meetings. Individuals contributed blinded pediatric CEUS cases following a set format of information - Supplementary Table 1). The collected data included: the examined organ, the clinical indication, the UCA dose, the final diagnosis and any adverse incidents. The primary aim of the EFSUMB EPR was to ascertain current applications of pediatric CEUS in European clinical practice. A further aim was to gather information about any adverse events and record any safety issues.

Analysis of the clinical data was from one time point (May 2020), and all information entered into the database at this time point was analyzed. The safety data was evaluated at a time point of September 2020. The drafting and publication of the report followed the stipulation of the EFSUMB policy on guidelines and position reports [30].

\section{Results}

A total of 60 cases were excluded as being outside the scope of the database purpose: endocavitary examinations $(n=7)$ and $>18$ years $(n=53)$. A total of 1463 children entered by 19 European centers up to May 2020 were suitable for the primary clinical analysis, and 1676 suitable for the secondary safety analysis were entered up to September 2020 ( $\triangleright$ Supplementary Table 2). All recorded intravenous CEUS examinations were performed using SonoVue (Bracco SpA, Milan) and considered for safety analysis.

\section{Ultrasound Contrast Agent (SonoVue) Dose}

A single injection was used in 1309/1463 (89.5\%), while 154/1463 (10.5\%) required multiple injections during a single CEUS examination.

The current recommended dosages vary and include (a) $0.1 \mathrm{~mL}$ of SonoVue for each year of age or (b) standard single dose of $0.1 \mathrm{~mL}, 0.5 \mathrm{~mL}, 1 \mathrm{~mL}, 1.2 \mathrm{~mL}, 2.4 \mathrm{~mL}$ or $4.8 \mathrm{~mL}$ of SonoVue. Some authors prefer $0.1 \mathrm{ml}$ SonoVue for each year of age. The recommendation of the FDA for the dose of SonoVue/Lumason in children is based on body weight; $0.03 \mathrm{~mL} / \mathrm{kg}$ as an intravenous injection, up to a maximum of $2.4 \mathrm{~mL}$ per injection [24]. A commonly used dosing scheme is $0.6 \mathrm{ml}$ for children aged $0-$ 6 years, $1.2 \mathrm{ml}$ for those between 6 and 12 and $2.4 \mathrm{ml}$ for those older than 12 years.

The dosage recorded in the EFSUMB EPR varied from 0.1 to $4.8 \mathrm{~mL}$, and up to three injections in a single examination were administered. In the majority (1309/1463, $89.5 \%$ ), a single dose achieved adequate quality of examination, resulting in a shorter time of examination. Factors determining the required dose of the UCA included the age and weight of the patient, organ under examination and ultrasound equipment UCA sensitivity (e.g., manufacturer, software, transducer frequency).

The dose of SonoVue for a technically adequate diagnostic study was also assessed. In 277/1463 (18.9\%), a dose of $<1.0 \mathrm{ml}$ was administered, where the average patient age was 4.6 years. A dose of $1-1.8 \mathrm{ml}$ was used in 585/1463 (40.0\%) with an average age of 10.2 years. In 352/1463 (24.1\%), 2.0-2.4 ml of SonoVue was given, with an average age of 14 years. Finally, $4.8 \mathrm{ml}$ of SonoVue was administered in $41 / 1463$ (2.8\%) with an average age of 14.2 years. The age range for all doses was $1-17$ years. Data was incomplete in 208/1463 (14.2\%). This confirms that physicians abide by dosing recommendations but variable doses were administered based on particular requirements.

\section{Clinical Applications}

The organs examined included: liver (911/1463, 62.3\%), spleen (191/1463, $13.0 \%)$, kidney (147/1463, $10.0 \%)$, gastrointestinal tract $(51 / 1463,3.9 \%)$, testis $(35 / 1463,2.4 \%)$ and chest $(25 / 1463$, $1.7 \%)$. Less frequently reported uses included superficial structures $(23 / 1463,1.6 \%)$, adrenal gland $(20 / 1463,1.5 \%)$, gallbladder (7/1463, 0.5\%), pancreas (11/1463, 0.8\%), urogenital pelvis (20/ $1463,1.4 \%)$, vessels $(6 / 1463,0.4 \%)$ and head and neck $(8 / 1463$, $0.5 \%$ ). Overall, CEUS was regarded as useful in 1242/1463 (84.9\%) applications. - Supplementary Table 3 summarizes the clinical applications.

\section{Liver}

$79.6 \%$ of liver applications were for focal liver lesion (FLL) characterization and $20.4 \%$ for trauma assessment, similar to a questionnaire-based survey [28]. The diagnostic purpose in most cases was to confirm the benign or malignant nature of an FLL and if benign, to further characterize the nature of the benign abnormality.

\section{Spleen}

In the spleen, $53.3 \%$ of the cases were performed for trauma and $46.7 \%$ were performed for lesion characterization. The characterization of splenic focal lesions is established in the literature, where the presence of a focal lesion, although rare, is most often benign.

\section{Kidney}

Renal applications were performed for lesion characterization (73.6\%) and for assessment of renal trauma (26.4\%). This included diagnosis and follow-up of complicated infection (e.g., abscess), cystic masses and complicated cysts, renal trauma, infarction, cortical necrosis, transplants and tumor vascularity [31-33].

\section{Chest}

Both inflammatory and oncologic conditions have been investigated using CEUS, with the inflammatory conditions accounting for $67.7 \%$ and oncologic conditions for the remainder. Lung CEUS was mainly used to differentiate consolidated lung from cavitating pneumonia and lung abscess formation in children [34].

\section{Liver and kidney transplantation}

The application of CEUS in children following transplantation is likely to be of equal value compared with the adult population [35-38]. Issues addressed included vascular patency, areas of organ necrosis, assessment of new focal liver or renal lesions and the assessment of post-operative complications (e. g., fluid collections). 


\section{Adrenal gland}

$89.0 \%$ of adrenal examinations were performed for lesion characterization. $11.0 \%$ were examined for trauma. Adrenal CEUS has been used to differentiate hemorrhage and cystic areas from neoplasms and to characterize the enhancement pattern of tumors in adults, but rarely in children $[39,40]$.

\section{Gastrointestinal tract}

Gastrointestinal system examinations were divided between solitary lesion characterization (47.0\%) and diffuse disease assessment (53.0\%). The investigated solitary lesions included lymphangioma, polyps, and mesenteric fibroma. A CEUS examination was commonly used to investigate abscesses in gastrointestinal disorders but was also used to differentiate between active and quiescent inflammatory bowel disease and to evaluate the outcome of therapeutic strategies $[41,42]$.

\section{Pelvis}

A total of 20 cases examining pelvic components of the urogenital system were recorded. Applications included: ovary (60.0\%) for ovarian torsion and ovarian lesion characterization, with demonstration of lack of enhancement in simple and hemorrhagic cysts. In the urinary bladder (40.0\%), the UCA was administered for evaluation of focal lesions and demonstration of any vascular enhancement, distinguishing viable tissue from debris.

\section{Testis}

A total of 35 cases of testicular CEUS were included. $20.0 \%$ were performed for the diagnosis of spermatic cord torsion and/or segmental infarction, $8.0 \%$ for the evaluation of complicated inflammatory conditions (e. g., epididymo-orchitis) and $64.0 \%$ for focal lesion characterization. CEUS was valuable for the confident establishment of benign nature of epidermoid cysts [43].

\section{Head and neck}

A total of eight head and neck cases were included. All were performed to characterize a focal lesion. In three (37.5\%) cases, CEUS was not deemed diagnostically useful. The reported abnormalities included lymphoma, abscess, and a giant cell tumor.

\section{Safety Considerations}

No side effects related to the intravenous administration of the UCA, SonoVue, were reported in 1657/1676 (98.9\%). 19 children (1.1\%) experienced adverse reactions ( $\triangleright$ Supplementary Table 4).

In a 16-year-old girl 1/1657 (0.06\%) (Patient 14), a hyperventilation attack reported prior to injection was considered a nocebo side effect $[44,45]$. In three patients (Patients 4, 5 and 6), mild symptoms occurred 4-8 hours after the examination procedure but were unlikely attributable to the UCA since it is eliminated within minutes from the body.

With the remaining 15 patients, post-injection hypersensitivity reactions were categorized as mild $(6 / 1657 ; 0.4 \%)$, moderate (5/1657; $0.3 \%)$, and severe $(4 / 1657 ; 0.2 \%)$ on a clinical severity grading system. The overall reaction rate was estimated at $0.9 \%$ [46]. Most mild hypersensitivity reactions symptoms have been previously described in the SonoVue/Lumason "Summary of Product Characteristic” (SPC), e. g. tachycardia, erythema, nausea, vomiting, headache, and hypotension [47]. However, a previously unreported "stupor-like" reaction in two cases (Patients 17 and 18) was observed. In both of these cases, classified as mild hypersensitivity reactions, a noticeable abrupt "calming down" of the patient without other evident physiological changes was seen. In addition, a slow response to commands was observed in the case of an older child (Patient 17).

There were five hypersensitivity reactions categorized as moderate with an onset from 50 seconds to 15 minutes and a need for drug administration (Patients 2, 7, 11, 12 and 13). The four hypersensitivity reactions graded as severe showed a rapid onset from 43 to 180 seconds (Patients 1, 3, 9 and 10) with loss of consciousness in two children. All severe hypersensitivity reactions were successfully treated with full recovery. No case of death was recorded.

\section{Discussion}

The EFSUMB EPR has provided a 'snapshot' of the current situation in European countries with regards to the application of CEUS in the diagnosis and management of pediatric patients. The usefulness of the technique is demonstrated by the extensive practice despite the "off-label" applications of intravenous UCA in pediatric patients [48]. Intravenous application of SonoVue/(Lumason is licensed for the evaluation of FLL in the United States of America, but not in Europe [24]. This has not deterred European investigators who have investigated many organs with CEUS and indicates that practitioners are mindful of the usefulness of CEUS examination, which is a real-time, child-friendly, repeatable examination without issues associated with radiation. The position of a US examination within imaging for the pediatric patient is established and the addition of a CEUS examination further improves diagnostic capabilities [21, 49]. The previous literature using CEUS in children demonstrates this usefulness and also indicates the "boldness" of many practitioners in establishing this technique [50-60].

The safety of CEUS has been well documented in adult patients $[61,62]$, and there have been some reports of the safety in children, assessing smaller numbers, with a similar safety profile as that seen in adults $[53,63-66]$. The EFSUMB guidelines and position papers on CEUS have reviewed all available evidence and indicated that CEUS is a safe and effective examination in adults [6769]. The series of Mao et al. [66], specifically investigating pediatric patients, reports an adverse reaction rate of 6/312 (1.92\%), compared with a reaction rate of $0.9 \%$ in the current study.

The contraindications documented by manufacturers in adults apply to children and include a history of known hypersensitivity to the active substance, right-to-left cardiac shunts (the FDA has recently removed this contraindication for intravenous use of Lumason), severe pulmonary hypertension and uncontrolled systemic hypertension [70]. The safety profile for SonoVue in adults suggests an overall rate of adverse events that is comparable to that of the administration of contrast media used in MR imaging and considerably lower than that of iodinated contrast media 
used in CT imaging $[8,61,62,71]$. However, all precautions for the management of adverse reactions should be in place before using a UCA in a child, and the examination is best performed in a dedicated hospital-based department, with expertise available to manage any reactions.

The anaphylactic reaction reported in a 4-year-old boy ( $\triangleright$ Supplementary Table 4, Patient 3) was investigated for allergy after the incident, revealing the child's sensitivity to polyethylene glycol (PEG), a bio-inert, thermoelastic linear hydrophilic polymer with the ability to increase stability and prolong in vivo circulation time of the liposomes. The vial of the SonoVue/Lumason in addition to the sulfur hexafluoride gas contains PEG 4000, distearoylphosphatidylcholine (DSPC), dipalmitoylphosphatidylglycerol sodium (DPPG-Na) and palmitic acid. Following reconstitution, the suspension of PEGylated sulfur hexafluoride microspheres is composed of sulfur hexafluoride gas in the core surrounded by an outer shell monolayer of phospholipids consisting of DSPC and DPPG-Na with palmitic acid as a stabilizer. All of these substances can be considered as a potential trigger of the hypersensitivity reaction referred to as complement activation-related pseudo allergy (CARPA), which is classified as a non-IgE-mediated pseudo allergy caused by the activation of the complement system [7274]. With this mechanism, complement is activated in both the classic and alternative pathways, resulting in an increase in C3a and $\mathrm{C} 5$ a anaphylatoxins that trigger mast cells and basophils for a secretory response underlying hypersensitivity reactions. Again, this emphasizes the need to perform a CEUS examination in a location that has access to resuscitation equipment and medical expertise support for resuscitation of the pediatric patient [18, 69]. The results from the current patient profile from the EFSUMB EPR confirms the safety profile of the UCA, SonoVue, in children.

Characterization of FLL in children is the most commonly reported application of pediatric intravenous CEUS in the EFSUMB EPR. Previous studies have reported evaluation of FLL in children, confirming the feasibility, safety and high diagnostic accuracy of CEUS for the characterization of FLL similar to CT and MR imaging $[51,54,64,75]$. The information from the EFSUMB EPR database indicates that the investigators are applying the adult patient pattern of CEUS findings when evaluating the characteristics of a pediatric FLL, particularly assessing the potential for malignancy, observing washout as the marker for malignancy. In addition, benign lesions are being assessed based on adult dynamics of the liver enhancement phases for differentiating between different benign FLLs [76]. Current literature pertaining to the assessment of FLLs is nearly exclusively adult-based, and validation in the pediatric population is needed $[77,78]$.

CEUS is a reliable tool in the diagnosis and follow-up of solid organ injuries in adults and is developing into a useful imaging strategy in children [60, 79-81]. Pediatric patients who sustain low to moderate energy traumatic events often require an initial CECT to identify the site of injury, and can be followed up with targeted CEUS at the site of solid organ injury [60]. This allows for repeated examinations without the need for CE-CT and the consequently increased radiation dose. The better spatial and temporal resolution of the CEUS examination is likely to identify complications such as a pseudoaneurysm more readily than CE-CT $[60,82]$. Diagnosis and follow-up of splenic, hepatic, renal and pancreatic trauma in children is often possible using CEUS. The recommendations for CEUS in trauma are detailed in the EFSUMB guidelines and are as follows: (a) in hemodynamically stable patients with isolated, low or moderate energy blunt abdominal trauma; (b) in patients with indeterminate or normal CECT findings; (c) in the follow-up of traumatic injuries that are managed conservatively in order to ensure resolution of the lesions or detect any associated complications, including pseudoaneurysm formation [18, 69]. The EFSUMB EPR database confirms that this is the accepted practice, with CEUS becoming an established follow-up imaging technique in children.

Other applications were varied, with applications in niche areas such as the testis and the neck used in a few children. Application in renal disease follows that in adults, with emphasis on the appearances of solid and cystic changes. Application in the assessment of inflammatory bowel disease was noted and may well develop into a particularly useful technique in children, thereby avoiding life-long MR and CT imaging [83].

There are a number of limitations to this report. Firstly, the data contribution procedure is optional and not mandatory for all fields, meaning that in some cases the information is not provided by the contributor, thus hindering accurate analysis of some aspects of the dataset. Secondly, there is no detailed information regarding the exact perfusion characteristics of lesions on CEUS. This would have made data entry more problematic and timeconsuming. In general, the interpretation and assessment of the data is rather subjective, for example when it comes to the assessment of whether CEUS was helpful or not. Finally, there is often no histologic confirmation, hindering robust analysis of the diagnostic accuracy of CEUS. The strength of the database lies in the reporting of any adverse events, as this was diligently undertaken, and the overall incidence is likely an accurate representation in this cohort of patients and remains low. However, it is acknowledged that much larger numbers are needed to fully establish the safety of CEUS in children.

The present assessment and the EFSUMB EPR is important as the database documents the safety, efficiency, and accuracy of CEUS in pediatric applications. Furthermore, the EFSUMB EPR serves as a "think tank" where everyone can share experiences, thereby building a body of evidence and evaluating new CEUS applications as they arise. The EFSUMB EPR acts as a "radar" for the detection and documentation of adverse UCA reactions. The EFSUMB EPR has strengthened the impression of a good safety profile of UCA in children. The results of the EFSUMB EPR also give insight into the daily use of CEUS in Europe and the probable growth in the number of practitioners performing this imaging technique [84].

\section{Conflict of Interest}

The authors declare speakers honoraria as follows:

Christoph F Dietrich: Advisory Board Member, Hitachi, Siemens Healthineers, Mindray. Speaker honoraria: Hitachi, Siemens, Mindray, Bracco, Pentax, GE, AbbVie. Research grant: Supersonic, Mindray, GE. Paul Sidhu, speaker honoraria: Bracco SpA, Siemens AG, Samsung Inc.. Tim Gibran Yusuf: Speaker honoraria: Siemens Healthineers, Bracco. Vito Cantisani receives lecture fees from Bracco, Samsung, Canon. All the other authors have declared no conflict of interest. 
[1] Starkey E, Sammons HM. Sedation for radiological imaging. Arch Dis Child Educ Pract Ed 2011; 96: 101

[2] Sammons HM, Edwards J, Rushby R et al. General anaesthesia or sedation for paediatric neuroimaging: current practice in a teaching hospital. Archives of Disease in Childhood 2011; 96: 114

[3] Guzel A, Atli A, Dogan E et al. Magnetic resonance imaging in children under anesthesia: the relationship between the degree of information provided to parents and parents' anxiety scores. Biomed Res Int 2014; 2014/05/25: 425107

[4] Voepel-Lewis T, Tait AR, Malviya S. Separation and induction behaviors in children: Are parents good predictors? Journal of PeriAnesthesia Nursing 2000; 15: 6-11

[5] Malviya S, Voepel-Lewis T, Prochaska G et al. Prolonged recovery and delayed side effects of sedation for diagnostic imaging studies in children. Pediatrics 2000; 105: E42

[6] Malviya S, Voepel-Lewis T, Tait AR et al. Sedation/analgesia for diagnostic and therapeutic procedures in children. Journal of PeriAnesthesia Nursing 2000; 15: 415-422

[7] Katayama H, Yamaguchi K, Kozuka T et al. Adverse reactions to ionic and nonionic contrast media: A report from the Japanese Committee on the Safety of Contrast Media. Radiology 1990; 175: 621-628

[8] Hunt CH, Hartman RP, Hesley GK. Frequency and Severity of Adverse Effects of lodinated and Gadolinium Contrast Materials: Retrospective Review of 456930 Doses. Am J Roentgenol 2009; 193: 1124-1127

[9] Dillman JR, Ellis JH, Cohan RH et al. Frequency and Severity of Acute Allergic-Like Reactions to Gadolinium-Containing IV Contrast Media in Children and Adults. Am J Roentgenol 2007; 189: 1533-1538

[10] Kanal E, Tweedle MF. Residual or Retained Gadolinium: Practical Implications for Radiologists and Our Patients. Radiology 2015; 275: 630-634

[11] Elbeshlawi I, AbdelBaki MS. Safety of Gadolinium Administration in Children. Pediatric Neurology 2018; 86: 27-32

[12] Donnelly LF. Reducing Radiation Dose Associated with Pediatric CT by Decreasing Unnecessary Examinations. Am J Roentgenol 2005; 184: 655-657

[13] Brenner DJ, Hall E]. Computed Tomography - an increasing source of radiation exposure. N Engl J Med 2007; 357: 2277-2284

[14] Brenner DJ, Hall EJ. Cancer risks from CT scans: now we have data, what next? Radiology 2012; 265: 330-331

[15] Brenner DJ, Elliston C, Hall E] et al. Estimated risks of radiation-induced fatal cancer from pediatric CT. Am J Roentgenol 2001; 176: 289-296

[16] Pearce MS, Salotti JA, Little MP et al. Radiation exposure from CT scans in childhood and subsequent risk of leukaemia and brain tumours: a retrospective cohort study. Lancet 2012; 380: 499-505

[17] Muhogora WE, Ahmed NA, AlSuwaidi JS et al. Paediatric CT examinations in 19 developing countries: frequency and radiation dose. Radiation Protection Dosimetry 2010; 140: 49-58

[18] Sidhu PS, Cantisani V, Deganello A et al. Role of contrast-enhanced ultrasound (CEUS) in paediatric practice: An EFSUMB position statement. Ultraschall in Med 2017; 38: 33-43

[19] Back S], Maya C, Darge K et al. Pediatric contrast-enhanced ultrasound in the United States: a survey by the Contrast-Enhanced Ultrasound Task Force of the Society for Pediatric Radiology. Pediatric Radiology 2018; 48: 852-857

[20] Darge K. Voiding urosonography with US contrast agent for the diagnosis of vesicoureteric reflux in children: an update. Pediatric Radiology 2010; 40: 956-962
[21] Sellars ME, Deganello A, Sidhu PS. Paediatric contrast-enhanced ultrasound (CEUS); a technique that requires co-operation for rapid implementation into clinical practice. Ultraschall in Med 2014; 35: 203-206

[22] Piskunowicz M, Kosiak W, Irga N. Why can't we use second generation ultrasound contrast agents for the examination of children? Ultraschall in Med 2011; 32: 83-86

[23] Piskunowicz M, Kosiak W, Batko T. Intravenous application of secondgeneration ultrasound contrast agents in children: a review of the literature. Ultraschall in Med 2012; 33: 135-140

[24] Food \& Drug Administration. MARCH 2016 - APPROVED DRUG PRODUCT LIST. 2016 http://www.fda.gov/downloads/drugs/developmentapproval process/ucm071120.pdf

[25] Bazzano ATF, Mangione-Smith R, Schonlau M et al. Off-Label Prescribing to Children in the United States Outpatient Setting. Academic Pediatrics 2009; 9: 81-88

[26] Knopf H, Wolf IK, Sarganas G et al. Off-label medicine use in children and adolescents: results of a population-based study in Germany. BMC Public Health 2013; 13: 631

[27] Pandolfini C, Bonati M. A literature review on off label drug use in children. Eur J Pediatr 2005; 164: 552-558

[28] Riccabona M. Application of a second-generation US contrast agent in infants and children - a European questionnaire-based survey. Pediatr Radiol 2012; 42: 1471-1480

[29] Rosado E, Riccabona M. Off-label use of ultrasound contrast agents for intravenous applications in children. Analysis of the existing literature. J Ultrasound Med 2016; 35: e21-e30

[30] Jenssen C, Gilja OH, Serra AL et al. European Federation of Societies for Ultrasound in Medicine and Biology (EFSUMB) Policy Document Development Strategy: Clinical Practice Guidelines, Position Statements and Technological Reviews. Ultrasound Int Open 2019; 05: E2-E10

[31] Riccabona M, Vivier PH, Ntoulia A et al. ESPR uroradiology task force imaging recommendations in paediatric uroradiology, part VII: standardised terminology, impact of existing recommendations, and update on contrast-enhanced ultrasound of the paediatric urogenital tract. Pediatr Radiol 2014; 44: 1478-1484

[32] Riccabona M, Avni FE, Damasio MB et al. ESPR Uroradiology Task Force and ESUR Paediatric Working Group - Imaging recommendations in paediatric uroradiology, Part V: childhood cystic kidney disease, childhood renal transplantation and contrast-enhanced ultrasonography in children. Pediatr Radiol 2012; 42: 1275-1283

[33] Harkanyi Z. Potential applications of contrast-enhanced ultrasound in pediatric patients. Ultrasound Clin North Am 2013; 8: 403-422

[34] Deganello A, Rafailidis V, Sellars ME et al. Intravenous and Intracavitary Use of Contrast-Enhanced Ultrasound in the Evaluation and Management of Complicated Pediatric Pneumonia. J Ultrasound Med 2017; 36: 1943-1954

[35] Berry JD, Sidhu PS. Microbubble contrast-enhanced ultrasound in liver transplantation. Eur Radiol 2004; 14: P96-P103

[36] Bonini G, Pezzotta G, Morzenti C et al. Contrast-enhanced ultrasound with SonoVue in the evaluation of postoperative complications in pediatric liver transplant recipients. J Ultrasound 2007; 10: 99-106

[37] Sidhu PS, Shaw AS, Ellis SM et al. Microbubble ultrasound contrast in the assessment of hepatic artery patency following liver transplantation: role in reducing frequency of hepatic artery arteriography. Eur Radiol 2004; $14: 21-30$

[38] Torres A, Koskinen SK, Gjertsen $\mathrm{H}$ et al. Contrast-Enhanced Ultrasound for identifying circulatory complications after liver transplants in children. Pediatr Transplant 2019; 23: e13327

[39] Al Bunni F, Deganello A, Sellars ME et al. Contrast-enhanced ultrasound (CEUS) appearances of an adrenal phaeochromocytoma in a child with Von Hippel-Lindau disease. J Ultrasound 2014; 17: 307-311 
[40] Rafailidis V, Deganello A, Sellars ME et al. Pediatric adrenal trauma: evaluation and follow-up with contrast-enhanced ultrasound (CEUS). J Ultrasound 2017; 20: 325-331

[41] Pecere S, Holleran G, Ainora ME et al. Usefulness of contrast-enhanced ultrasound (CEUS) in Inflammatory Bowel Disease (IBD). Digestive and Liver Disease 2018; 50: 761-767

[42] Chiorean L, Schreiber-Dietrich D, Braden B et al. Ultrasonographic imaging of inflammatory bowel disease in pediatric patients. World J Gastroenterol 2015; 21: 5231-5241

[43] Patel K, Sellars ME, Clarke JL et al. Features of testicular epidermoid cysts on contrast enhanced ultrasound and real time elastography. J Ultrasound Med 2012; 31: 1115-1122

[44] Rojas-Mirquez JC, Rodriguez-Zuniga MJM, Bonilla-Escobar FJ et al. Nocebo effect in randomized clinical trials of antidepressants in children and adolescents: systematic review and meta-analysis. Front Behav Neurosci 2014; 8: 375

[45] Pan Y, Kinitz T, Stapic M et al. Minimizing Drug Adverse Events by Informing About the Nocebo Effect-An Experimental Study. Front Psychiatry 2019; 10: 504

[46] Brown SGA. Clinical features and severity grading of anaphylaxis. Journal of Allergy and Clinical Immunology 2004; 114: 371-376

[47] Bracco. Lumason Prescribing Information. 2016 http://imaging.bracco. com/sites/braccoimaging.com/files/technica_sheet_pdf/US-20160330LUMASON-PI_0.pdf

[48] Sidhu PS, Choi BI, Bachmann Nielsen M. The EFSUMB guidelines and recommendations on the clinical practice of contrast enhanced ultrasound (CEUS): a new dawn for the escalating use of this ubiquitous technique. Ultraschall in Med 2012; 32: 5-7

[49] Seitz K, Strobel D. A Milestone: Approval of CEUS for Diagnostic Liver Imaging in Adults and Children in the USA. Ultraschall in Med 2016; 37 : 229-232

[50] Schreiber-Dietrich DG, Cui XW, Piscaglia F et al. Contrast Enhanced Ultrasound in Pediatric Patients: A Real Challenge. Z Gastroenterol 2014; 52: 1178-1184

[51] Jacob ], Deganello A, Sellars ME et al. Contrast Enhanced Ultrasound (CEUS) Characterization of Grey-scale Sonographic Indeterminate Focal Liver Lesions in Paediatric Practice. Ultraschall in Med 2013; 34: 529-540

[52] Yusuf GT, Sellars ME, Huang DY et al. Cortical Necrosis Secondary to Trauma in a Child: Contrast-enhanced ultrasound comparable to Magnetic Resonance Imaging. Pediatr Radiol 2014; 44: 484-487

[53] Yusuf GT, Sellars ME, Deganello A et al. Retrospective Analysis of the Safety and Cost Implications of Pediatric Contrast-Enhanced Ultrasound at a Single Center. Am J Roentgenol 2016; 208: 446-452

[54] Stenzel M. Intravenous contrast-enhanced sonography in children and adolescents - a single center experience. J Ultrason 2013; 13: 133-144

[55] Knieling F, Strobel D, Rompel O et al. Spectrum, Applicability and Diagnostic Capacity of Contrast-Enhanced Ultrasound in Pediatric Patients and Young Adults after Intravenous Application - A Retrospective Trial. Ultraschall in Med 2016; 37: 1-8

[56] McCarville MB, Kaste SC, Hoffer FA et al. Contrast-enhanced sonography of malignant pediatric abdominal and pelvic solid tumors: preliminary safety and feasibility data. Pediatr Radiol 2012; 42: 824-833

[57] McCarville MB, Coleman JL, Guo J et al. Use of Quantitative Dynamic Contrast-Enhanced Ultrasound to Assess Response to Antiangiogenic Therapy in Children and Adolescents With Solid Malignancies: A Pilot Study. Am J Roentgenol 2016; 206: 933-939

[58] Menichini G, Sessa B, Trinci M et al. Accuracy of contrast-enhanced ultrasound (CEUS) in the identification and characterization of traumatic soild organ lesionsin children: a retrospective comparison with baseline US and CEMDCT. Radiol Med 2015; 120: 989-1001
[59] Valentino M, Serra C, Zironi G et al. Blunt Abdominal Trauma: Emergency Contrast-Enhanced Sonography for Detection of Solid Organ Injuries. Am J Roentgenol 2006; 186: 1361-1367

[60] Durkin N, Deganello A, Sellars ME et al. Post-traumatic liver and spleen pseudoaneurysms in children: diagnosis, management and follow-up screening using contrast enhanced ultrasound (CEUS). J Pediat Surg 2016; 51: 289-292

[61] Piscaglia F, Bolondi L. The safety of SonoVue in abdominal applications: retrospective analysis of 23188 investigations. Ultrasound in Med Biol 2006; 32: 1369-1375

[62] Tang C, Fang K, Guo Y et al. Safety of Sulfur Hexafluoride Microbubbles in Sonography of Abdominal and Superficial Organs: Retrospective Analysis of 30222 Cases. J Ultrasound Med 2017; 36: 531-538

[63] Coleman JL, Navid F, Furman WL et al. Safety of ultrasound contrast agents in the pediatric oncologic population: a single-institution experience. Am J Roentgenol 2014; 202: 966-970

[64] Piskunowicz M, Kosiak W, Batko T et al. Safety of intravenous application of second generation ultrasound contrast agent in children: prospective analysis. Ultrasound Med Biol 2015; 41: 1095-1099

[65] Torres A, Koskinen SK, Gjertsen $\mathrm{H}$ et al. Contrast-enhanced ultrasound using sulfur hexafluoride is safe in the pediatric setting. Acta Radiologica 2017; 58: 1395-1399

[66] Mao M, Xia B, Chen W et al. The Safety and Effectiveness of Intravenous Contrast-Enhanced Sonography in Chinese Children-A Single Center and Prospective Study in China. Front Pharmacol 2019; 10: 1447

[67] Claudon M, Cosgrove D, Albrecht T et al. Guidelines and good clinical practice recommendations for contrast enhanced ultrasound (CEUS) update 2008. Ultraschall in Med 2008; 29: 28-44

[68] Piscaglia F, Nolsoe C, Dietrich C et al. The EFSUMB Guidelines and Recommendations on the Clinical Practice of Contrast Enhanced Ultrasound (CEUS). Update 2011 on non-hepatic applications. Ultraschall in Med 2012; 1: 11-12

[69] Sidhu PS, Cantisani V, Dietrich CF et al. The EFSUMB Guidelines and Recommendations for the Clinical Practice of Contrast-Enhanced Ultrasound (CEUS) in Non-Hepatic Applications: Update 2017 (Long Version). Ultraschall in Med 2018; 39: e2-e44

[70] European Medicines Agency. SonaVue. Summary of product characteristics, 25 May 2018. https://www.ema.europa.eu/en/documents/ product-information/sonovue-epar-product-information_en.pdf. Accessed December 9, 2019. EMA 2018

[71] Wang CL, Cohan RH, Ellis JH et al. Frequency, outcome, and appropriatness of treatment of nonionic iodinated contrast media reactions. Am J Roentgenol 2008; 191: 409-415

[72] Kozma GT, Shimizu T, Ishida T et al. Anti-PEG antibodies: Properties, formation, testing and role in adverse immune reactions to PEGylated nano-biopharmaceuticals. Advanced Drug Delivery Reviews 2020

[73] Szebeni J. Complement activation-related pseudoallergy caused by amphiphilic drug carriers: the role of lipoproteins. Curr Drug Deliv 2005; 2: 443-449

[74] Szebeni ]. Complement activation-related pseudoallergy: a stress reaction in blood triggered by nanomedicines and biologicals. Mol Immunol 2014; 61: 163-173

[75] Anupindi SA, Biko DM, Ntoulia A et al. Contrast-enhanced US assessment of focal liver lesions in children. Radiographics 2017; 37: 1632-1647

[76] Fang C, Bernardo S, Sellars ME et al. Contrast-enhanced ultrasound in the diagnosis of pediatric focal nodular hyperplasia and hepatic adenoma: interobserver reliability. Pediatric Radiology 2019; 49: 82-90

[77] Dietrich CF, Nolsoe CP, Barr RG et al. Guidelines and Good Clinical Practice Recommendations for Contrast-Enhanced Ultrasound (CEUS) in the Liver-Update 2020 WFUMB in Cooperation with EFSUMB, AFSUMB, AIUM, and FLAUS. Ultrasound in Medicine \& Biology 2020; 46: 2579-2604 
[78] Dietrich CF, Nolsoe CP, Barr RG et al. Guidelines and Good Clinical Practice Recommendations for Contrast Enhanced Ultrasound (CEUS) in the Liver - Update 2020 - WFUMB in Cooperation with EFSUMB, AFSUMB, AIUM, and FLAUS. Ultraschall in Med 2020 41: 562-585

[79] Catalano O, Aiani L, Barozzi L et al. CEUS in abdominal trauma: multi-center study. Abdominal Imaging 2009; 34: 225-234

[80] Valentino M, Serra C, Pavlica P et al. Blunt Abdominal Trauma: Diagnostic Performance of Contrast-enhanced US in Children. IInitial Experience. Radiology 2008; 246: 903-909
[81] Miele V, Buffa V, Stasolla A et al. Contrast enhanced ultrasound with second generation contrast agent in traumatic liver lesions. Radiol Med 2004; 108: 82-91

[82] Makin E, Durkin N, Deganello AM et al. Reply to letter to the editor. Journal of Pediatric Surgery 2017; 52: 368-369

[83] Kljucevsek D, Vidmar D, Urlep D et al. Dynamic contrast-enhanced ultrasound of the bowel wall with quantitative assessment of Crohn's disease activity in childhood. Radiol Oncol 2016; 50: 347-354

[84] Sidhu PS, Cantisani V, Deganello A et al. Authors Reply to Letter: Role of Contrast-Enhanced Ultrasound (CEUS) in Paediatric Practice: An EFSUMB Position Statement. Ultraschall in Med 2017; 38: 447-448 